\title{
Configuraciones emergentes de circulación y lectura en el entorno digital: el caso de Bajalibros.com
}

\section{Szpilbarg, Daniela}

Resumen:

La digitalización de contenidos ha cambiado las técnicas de producción editorial y las prácticas de lectura. En este artículo recorreremos teóricamente los cambios ocurridos en la cadena de la publicación de contenidos editoriales. Luego describiremos la emergencia de nuevos soportes y actores que complejizan las instancias tradicionales de la cultura impresa (dispositivos móviles, influencia de las redes sociales en la lectura digital, desarrollo de tiendas en línea, el surgimiento de bibliotecas virtuales, etc.). Por último, analizaremos un caso para comprender estas transformaciones: la plataforma online de venta de ebooks Bajalibros.com,

\section{Cuadernos del Centro de Estudios de Diseño y Comunicación N ${ }^{072}$}

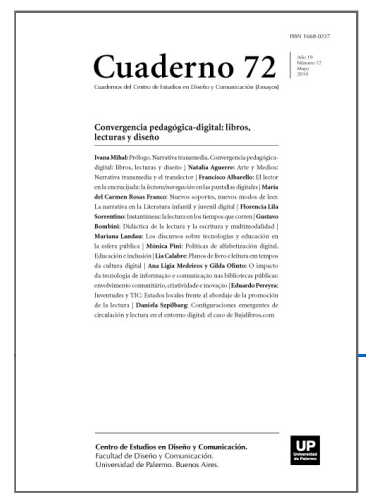

ISSN: 1668-0227

Convergencia

pedagógica-digital:

libros, lecturas y

diseño

Año XIX, Mayo 2019, Buenos Aires,

descargar PDF

ver índice de la publicación

Ver todos los libros de la publicación

compartir en Facebook

cc) ()(2) Esta obra está bajo una Licencia Creative EY NC SA Commons Atribución-NoComercialCompartirlgual 4.0 Internacional

que se presenta como "la primera tienda de libros digitales en español de Latinoamérica"

Palabras clave: Digitalización - Editor - Librerías - Ebooks - Plataformas.

(*) Licenciada en Sociología. Doctora en Ciencias Sociales (UBA). Becaria Postdoctoral del CONICET. Docente en la materia "Teoría Social Latinoamericana" (UBA). Co-coordinadora del Núcleo de Estudios del Libro y la Edición (CIS-IDES). Su tesis de doctorado se titula "Las tramas de la edición mundializada. Transformaciones y horizontes del campo editorial en Argentina (1998-2013)".

Introducción

Este artículo propone una reflexión sobre el modo en que la cadena de producción de libros se ha visto afectada, en los últimos años, por las transformaciones que la digitalización de contenidos provocó a la cultura escrita. La reflexión supone considerar que la palabra escrita puede transmitirse a través de distintos soportes. Según Roger Chartier, los distintos soportes materiales de la escritura han sido los que a lo largo de diversas épocas, 
cumplen la función de aquietar el miedo a la pérdida. El análisis sociológico que propone este artículo a través de un referente concreto permitirá no solamente historizar las transformaciones de la cultura escrita, sino problematizar las nociones de texto, en tanto documento escrito que es leído y que tiene una cierta forma física.

Uno de los primeros historiadores que reflexionó sobre el tema de los textos y la relación con los soportes fue Robert Darnton, quien ya a comienzos de la década de 1980 escribió un fundamental trabajo titulado “¿Qué es la historia del libro?". Allí daba cuenta del estadio incipiente de los estudios sobre el libro, a la vez que intentaba plasmar un primer análisis acerca de la circulación del libro impreso en el marco de lo que llamó "el circuito de la comunicación", exponiendo los actores principales que forman parte de este ciclo vital del libro, un recorrido que va del autor al lector, pasando por el editor, el impresor, el librero y los distribuidores. Darnton se refiere a la "historia social y cultural de la comunicación por medio de la imprenta" (Darnton, 2010, p. 117), concentrándose en la experiencia literaria de los lectores y afirmando que la historia del libro es un campo de estudios que comienza desde el momento de la invención de la imprenta de Gütenberg hasta las transformaciones en la cultura escrita mediante la incorporación de nuevas tecnologías en la actualidad, campo de estudios que, según él, debe ser "internacional en sus dimensiones e interdisciplinario en su método" (Darnton, 2010, p. 146). Es significativo pensar cómo este esquema debería pensarse en la actualidad a la luz de las transformaciones generadas por la digitalización, que alteran este esquema del libro impreso, abriendo el circuito a libros electrónicos y una cantidad de actores como desarrolladores de software, así como plataformas de venta de libros online, que Darnton no hubiera imaginado en 1982 cuando escribió el texto.

Volviendo a lo anterior, la novedad introducida por Chartier, otro historiador, se vincula con un énfasis mayor en la materialidad de los objetos y en la transmisión y circulación de discursos. La forma física del objeto libro constituye un aspecto central a tener en cuenta para reconstruir las prácticas de edición y lectura: así, estudia los objetos impresos y sus formas materiales, así como las prácticas que significan los textos a partir del contacto con los libros considerados como objetos materiales. Por ende, no hay texto sin su soporte y es a partir de allí donde se conforma el espacio de construcción del sentido. El análisis de Chartier radica en la importancia de las formas en las que circularon los escritos para dar cuenta de su significación y las representaciones generadas por su lectura:

Las transacciones entre las obras y el mundo social no consisten únicamente en la apropiación estética y simbólica de objetos comunes, lenguajes y prácticas rituales o cotidianas (...) Conciernen más fundamentalmente a las relaciones múltiples, móviles, inestables, anudadas entre el texto y sus materialidades, entre la obra y sus inscripciones. El proceso de publicación, cualquiera que sea su modalidad, siempre es un proceso colectivo, que implica a numerosos actores y que no separa la materialidad del texto de la textualidad del libro... (Chartier, 2006, p. 12)

Ampliando el estudio del libro hacia la particularidad de la "cultura escrita", en principio podemos decir que lo impreso referiría a un mundo estructurado a través de la imprenta, aunque, si consideramos otras perspectivas, dentro del área de estudios acerca de la cultura escrita, podemos mencionar a autores como Jack Goody (1996), Walter Ong (1982) o Marshall McLuhan (1962), quienes han abordado procesos como el cambio de las culturas orales a las culturas escritas; el cambio de la alfabetización a la impresión -del manuscrito a la imprenta y luego a la producción de escritos cada vez más industrial-; y por último las transformaciones de la imprenta a la digitalización de contenidos. La relación entre la cultura textual y la comunicación social es muy grande, de modo tal que un teórico como Benedict Anderson (1983) desarrolló su teoría acerca de que la imprenta fue 
crucial para la formación de una conciencia nacional al darle una nueva fijeza al lenguaje, que ayudó a forjar la idea subjetiva de lo que era una "nación".

Llegando a la etapa contemporánea, los autores antedichos Robert Darnton (2010) y Chartier (2006), sugieren que la forma del texto electrónico plantea una nueva organización de los discursos basada principalmente en el hipertexto y la distinción entre distintos niveles textuales. La característica más sobresaliente del proceso de digitalización es que permite convertir en información elementos que antes estaban sujetos a condiciones espaciotemporales restringidas, lo cual se concretiza a partir del hipertexto. El concepto de lo hipertextual se convierte en una representación del salto cualitativo que los especialistas en informática han dado respecto del lector, ya que esta herramienta hipertextual proviene del software y lo que permite es enlazar y compartir información desde diversas fuentes a partir de un enlace asociativo, que puede aparecer en forma de hipervínculo o referencias cruzadas que van a otros documentos. El hipertexto, por otra parte, no se reduce solamente a posibilidades textuales, sino que aquello que puede enlazarse puede ser sonido o videos.

En relación a lo abordado, Juan Mendoza (2011) sostiene un esquema integrado por tres etapas, que implicarían un momento de hegemonía de la cultura letrada, luego la cultura industrial y luego la cibercultura. Lo industrial estaría marcado por un salto cuantitativo de la cultura por los nuevos medios tecnológicos, radio, TV: la ampliación de los públicos marcaría la diferencia entre la sociedad de masas y la cultura letrada. Así, a partir del siglo XX emerge la edad cibernética, que se integra con las anteriores y esta cibercultura, caracterizada por una "desjerarquización entre lo alto y lo bajo" (Mendoza 2011, p. 92), marca el momento de un nuevo tipo de ediciones. En la misma línea, cuando diversos autores como Castells describen la actual configuración social como "sociedad red" hacen referencia a un cambio profundo en los sistemas de comunicación, ya que una cultura no son sólo contenidos, sino también prácticas y medios de transmisión a través de los que se comunican los individuos. La división de las culturas en orales, gráficas y electrónicas hace referencia precisamente a los sistemas de transmisión de los diferentes contenidos. La "sociedad de la información" o "sociedad digital" se configura mediante la conjunción de dos elementos: la informática, tecnología de procesamiento de datos vinculada con la computadora como elemento central y las redes de comunicación: tecnología que posibilita la distribución de información digitalizada (Aguirre, 2009).

La digitalización y las tecnologías de la información y la comunicación transforman definitivamente el panorama de las industrias de contenidos. El sector editorial, dentro de la publicación de libros se desplaza desde una industria de movimientos lentos, localizada hacia un escenario más abierto, global, liviano, con más liquidez y una fuerte presencia de commodities (Hutnik, 2014). Con la posibilidad de la edición digital y el desarrollo de dispositivos de la lectura, las potenciales consecuencias para el formato impreso se debaten a nivel global. Ante la multiplicidad de posibilidades del libro digital, el libro físico como soporte legítimo aparece fuertemente cuestionado y transformado en su forma clásica. Esto se da, especialmente, en los libros académicos, por lo que los vínculos entre conocimiento y libro se modifican, "no solamente en el ámbito de la producción, sino también en la recepción y el consumo" (Hutnik y Saferstein, 2014, p. 39).ubjetiva de lo que era una "nación”.

En Argentina, si bien las cifras de producción no necesariamente se acompañan todavía con cifras similares de consumo, más del 15\% de las publicaciones registradas de libros, lo hicieron en formato electrónico (CERLALC, 2012; 2014). Las transformaciones de la industria editorial frente a las Tecnologías de Información y Comunicación son varias y 
Se dan en torno al impacto de la digitalización en el catálogo y en la política editorial, los formatos, dispositivos y prácticas de lectura, los canales de distribución y venta, la política de precios y el efecto sobre los recursos internos de la editorial. (Hutnik y Saferstein, 2014, p. 40)

En este contexto, el objetivo de nuestro artículo será exponer los principales efectos que la digitalización puede tener para el mundo de la edición, antes de enfocarnos en un referente de análisis específico: la plataforma de venta de libros Bajalibros.com, fundada en Argentina en 2011, como un ejemplo de emprendimiento digitaleditorial que se ha ido forjando al compás de estas transformaciones locales e internacionales de la industria de la edición. Como sostienen Neiman y Quaranta (2006), el caso es "un sistema delimitado en tiempo y espacio de actores, relaciones e instituciones sociales donde se busca dar cuenta de la particularidad del mismo en el marco de su complejidad" (Neiman y Quaranta, 2006, p. 220). El artículo utilizó un abordaje principalmente cualitativo1, aunque se utilizaron indicadores cuantitativos para pensar el análisis de este caso, como por ejemplo el impacto de la edición digital, a través de instituciones como la Cámara argentina del Libro (CAL), o el Centro Regional para el Fomento del Libro en América Latina y el Caribe (CERALC) que producen datos estadísticos y cuantitativos sobre el sector.

Adaptación de la industria editorial a la digitalización

La aparición y la masificación del ebook han generado y catalizado diversos cambios en toda la industria del libro. En principio, podemos ver algunos de esos cambios a través de la aparición de plataformas de autopublicación, la posibilidad de imprimir bajo demanda tiradas cortas, la lectura en soportes digitales, o el nacimiento de editoriales directamente digitales. Estas transformaciones -que se ven primero en el mundo anglosajón y que luego se trasladan a España y a América Latina- han producido distintas modificaciones en los distintos momentos de la cadena de valor tradicional del libro, y que afectan a autores, editores, libreros, librerías, distribuidoras, bibliotecas, y que por supuesto implican que estos actores vayan transformándose en busca de adaptarse a este proceso de implantación o coexistencia con los libros electrónicos.

Estos libros llamados "electrónicos", pueden funcionar en PDF, EPUB, pueden presentar o no DRM, y además pueden leerse en multiplicidad de dispositivos, no solamente la computadora, sino también el teléfono móvil y los diversos e-readers.

El sector editorial está integrado por diversos actores y etapas, como escritores, lectores, críticos, editores, libreros, y por distintos momentos: "creación o producción”, que contemplaría la producción intelectual de los textos; el sector "productivo-distributivo", que son los que se encargan de la elaboración material de los textos, es decir su inserción en un soporte determinado, y el momento del "consumo". El primer gran cambio que se percibe a partir de los medios electrónicos es la separación entre los textos y los soportes, es decir, la separación de información y soporte de la misma, ya que la información contenida en el soporte libro es susceptible de ser digitalizada. Este tema es problemático, ya que si consideramos que los "textos" pueden circular bajo otras formas que no sean los "libros", la institución editorial no sería ya necesaria para todos los textos. Un gran cambio tiene que ver, como hemos dicho, con la autonomía productiva: el autor puede ser su propio editor, es decir que puede controlar todo el proceso de edición de su propia obra. La informática le provee todo tipo de herramientas de producción (procesadores de textos, programas gráficos para diseño). Asimismo, existen dispositivos y plataformas como la que analizaremos en este trabajo para llegar directamente al público a través de las redes sociales como "autores independientes". 
Para historizar esta cuestión, vale la pena recordar que en octubre de 2009 se ponía a la venta el primer ereader de Amazon (el Kindle) y paralelamente fue lanzada la plataforma Google Books. En una primera instancia, esto tuvo por supuesto implicancias de índole contractual ya que la mayor parte de los contratos que existían no contemplaban la cesión de derechos digitales. A partir de la venta del e-book, se abarataron los costos de producción, porque ya no era necesaria la impresión ni el almacenamiento, sumado a que se transferían los costos de contar con una distribuidora a pactar con sistemas de software y plataformas online de venta. Por ende, el PVP (Precio de venta al público) disminuyó, al mismo tiempo que empeoró el tema de la piratería.

Al mismo tiempo, surgió para las distintas editoriales -sobre todo aquellas dedicadas a temas educativos o no ficción- de contar con los llamados "libros enriquecidos", a partir de posibilidades hipertextuales. Sumado a estas posibilidades, hay una cuestión con los mercados que también parece abrirse. El hecho de poder publicar un libro electrónico y venderlo a través de la web, permite que las editoriales aprovechen más el mercado de hispano-hablantes (alrededor de 450 millones de personas en el mundo), si bien, por supuesto, continúan existiendo los dominios y áreas en las que las plataformas pueden vender los libros. A partir de la digitalización de contenidos, ha ido surgiendo distintas posibilidades y modelos comerciales (venta por capítulos, préstamo digital, nuevas formas de promoción, hojear contenidos en línea, etc.).

En Argentina, se puede ver cómo algunas grandes editoriales (pertenecientes a grupos transnacionales, como Planeta o Penguin Random-House), han comenzado a digitalizar en formato Epub y a comercializar a través de sitios web de libros. Para el 2010, Google Books, que había en 2004 propuesto digitalizar 32 millones de libros, ya llevaba escaneados 7 millones de libros. Más allá de esto, que permitía solamente hojear el $20 \%$ de los libros, luego comenzó Google Edition, un sistema de visualización completa online de los libros sujetos a derechos de autor mediante distintas modalidades de pago. Surgen así progresivamente desde la década del 2000, distintos agregadores de contenidos, editoriales adaptadas al ebook, editoriales electrónicas, servicios de autopublicación en línea, y plataformas de impresión a demanda, como el caso de Bubok.com o el caso de Teseo en Argentina (editorialteseo.com). De hecho, el portal Bubok se presenta como "solución de publicación" para autores. Es decir, es dificultosa la auto-clasificación de estas páginas como plataformas o librerías. (Ver Figuras 1 y 2)

En conclusión, y volviendo a considerar los distintos actores y momentos de esta industria, es preciso plantear que el rol del editor en este contexto ha comenzado a presentar ciertos cambios (por lo menos en aquellas editoriales que comenzaron procesos de adaptación a la realidad del ebook). Lo que ocurre es que en las editoriales comienza a haber una presencia importante de los actores vinculados al software y por ende el editor pierde su rol como único "curador" de contenidos, sobre todo porque a partir de la existencia de plataformas de venta de ebooks, existe la posibilidad de la autoedición y venta de libros sin pasar por una editorial. Es el caso de plataformas como Bubok.com en España o la que analizaremos en este trabajo, Bajalibros.com de Argentina. Por lo antedicho, hay una pérdida también de importancia de los impresores y distribuidores, que dejan de ser imprescindibles.

Todos estos cambios de los que venimos hablando, ligados a la digitalización de las obras literarias, derivan en el lógico problema del derecho de autor, a partir de la imposibilidad de controlar las copias. Si el lector puede realizar múltiples copias a partir de un solo ejemplar digital, el negocio editorial podría resentirse. Es decir que la incidencia de este nuevo paradigma comunicacional sobre el sector editorial es alta, ya sea por el desvío de textos hacia la edición digital (que podrá ser realizado por los autores mismos, por nuevas empresas o por las 
mismas editoriales), por sistemas de edición dobles (digital e impresa) o por la producción de los nuevos tipos de "textos" multimedia a partir de prácticas hipertextuales (Aguirre, 2009). La modalidad de intervención del sector distribuidor también sufrirá cambios, ya que la posibilidad de intervenir de modo digital, reduciría el suministro de libros a las librerías, lugares que, por lo demás, ya no serán absolutamente necesarios a la hora de querer conseguir un libro. De hecho, como puede observarse, en los últimos años han surgido una cantidad de plataformas online de compra y venta de libros electrónicos, así como de compra de libros físicos a través de "librerías online".

La expansión en la digitalización de textos editados en papel, y la producción de textos en formato digital, provocó que a fines de la década del 2000 comenzaran a comercializarse dispositivos cuyo fin es transportar y permitir su lectura, al mismo tiempo que ofreciera las funciones de ajustar el tamaño de los textos, agregar comentarios, navegar por internet o participar en redes sociales y foros. Si bien el soporte tradicional en papel sigue siendo mayoritario, el crecimiento de los libros electrónicos fue sostenido en los últimos años. Hay un creciente número de sitios gratuitos donde se pueden descargar libros electrónicos. Además, la venta a través del portal de comercio electrónico estadounidense Amazon. com -que comercializa este formato desde 1995fue mayoritaria por sobre el formato en papel de libros durante 2009 (Ensinck, 2010), dos años después en que saliera a la venta el Kindle, primero de los sucesivos soportes móviles de e-book. Es preciso tener en cuenta que la aparición de estas tecnologías y sus consecuentes prácticas entran en tensión con las instituciones literarias tradicionales y las formas de edición conocidas, así como también ha cambiado a las personas en tanto lectores. Ya no se es "lector" como en décadas pasadas, ni estudiante, ni espectador de una película: hoy los individuos son también internautas. García Canclini refiere así a personas que leen, aprecian algo e interactúan, todo al mismo tiempo. Ser internauta supondría más acciones: mirar, leer, contestar correos y buscar información, lo cual aumenta para muchas personas la posibilidad de ser lectores y espectadores al mismo tiempo (García Canclini 2007).

Partiendo de la base de que hay una trama de producción autoral, editorial y comercial en relación a la obra, el soporte juega un rol importante ya que con el cambio de soporte aparece un nuevo modelo de transmisión de la información y por ende surgen actores que no pertenecen al mundo editorial, así como surgen, por ejemplo y atendiendo al caso del que hablábamos, los derechos digitales que un autor o una editorial puede tener sobre una obra. Arduo camino que debe la ley abrirse entre los avances vertiginosos de la tecnología. Es justamente en esta encrucijada donde aparecen además los debates en torno al rol que el Estado debe cumplir en la regulación de este tipo de situaciones. En el siguiente apartado nos enfocaremos en el caso seleccionado para analizar en este artículo. Proponemos la descripción de la plataforma Bajalibros.com, por considerar que nos permite tomarlo como prisma de análisis desde donde observar las transformaciones que la digitalización provocó en el mundo del libro impreso, desde la óptica del caso argentino.

El caso BajaLibros.com: hacia el modelo de comercialización digital en el marco del capitalismo informacional

En este apartado nos vamos a centrar en el análisis del caso de Bajalibros.com (Ver Figura 3), un portal de venta de libros electrónicos surgido en Argentina en 2011, y luego replicado también en otros países de América Latina. El análisis del caso nos permitirá contextualizar esta irrupción de la digitalización de contenidos escritos dentro de un contexto mayor de los procesos de valorización. Es preciso resaltar que nos encontramos ante una etapa del capitalismo de características salientes respecto de periodos anteriores. Se llama "capitalismo informacional" o "capitalismo cognitivo" para hacer referencia a la centralidad del conocimiento y la tecnología en 
los procesos de valorización y producción, con los efectos que esto supone a la hora de observar el comportamiento de diversos agentes que forman parte de los procesos de formación de valor en el área cultural.

En relación con esto, Dantas plantea que el antiguo modelo institucional de las comunicaciones que se desplegó desde la década de 1930 hasta la década de 1980 ha cambiado, provocando un cambio hacia la tercera Revolución Tecnológica: textos, imágenes y sonidos se transforman en bits y la digitalización de la información es la base técnica de la producción social general. El trabajo en el capitalismo informacional es un ejercicio de recolectar, compilar, reunir, procesar y relacionar datos (Dantas, 2003, p. 142).

El análisis del capitalismo de la década del 90 y comienzos del siglo veintiuno se vincula con la profundización de la internacionalización financiera y comercial y su vínculo con las Tecnologías de Información y comunicación como una clave que inaugura la época contemporánea. Por otro lado, el lenguaje y la comunicación se reconocen como centrales en este tipo de sistemas productivos. Según Martha Roldán, se advierte "un proceso de intensificación del tiempo para superar el espacio" (Roldán, 2008, p. 18) a fin de que se reduzca el tiempo total de rotación del capital. Y en consecuencia el tiempo se transforma -según Harvey (1998)- en la mayor fuente de valorización, acumulación y apropiación de rentas informacionales a nivel nacional e internacional. En definitiva, se habla de un gran cambio que indica que el trabajo fabril pierde su hegemonía, marcando la emergencia del trabajo inmaterial, un tipo de trabajo que crea bienes inmateriales como el conocimiento y la información.

En palabras de Dantas, "la información emerge como fuerza productiva determinante" (Dantas, 2003, p. 217) y esta "acumulación flexible" provoca cambios en las relaciones y prácticas del trabajo. En relación con esto, es indudable que estos cambios afectan a la industria editorial en diversos aspectos que hemos explorado anteriormente. Provocan además la necesidad de adoptar nuevas competencias a la hora del trabajo del editor como figura principal de las editoriales, así como también de las librerías, como espacios de distribución de los materiales textuales.

En este trabajo caracterizaremos uno de estos emprendimientos, que consideramos emblemático ya que nace precisamente como plataforma digital de venta de libros. Recordemos aquí que los intermediarios culturales han sido definidos por Bourdieu como un sector en expansión de una nueva clase media en ascenso, actores que "se hallan dedicados a la provisión de los bienes y servicios simbólicos: comercialización, publicidad, relaciones públicas, producción de radio y televisión..." (Featherstone, 1991, p. 87) a los que les podemos añadir, entre otros a los editores y nuevos críticos literarios, diseñadores, trabajadores del marketing, etc. Aparecen como "nuevos intelectuales", portadores y transmisores de símbolos y significados, nuevos estilos de vida y en la búsqueda de nuevas experiencias. La importancia de lo simbólico en el capitalismo cultural y cognitivo, convierte a los intermediarios culturales en productores de signos. En base a todo lo anterior, pasaremos a analizar fundamentalmente, la relación que el campo editorial mantiene con las tecnologías. Esta relación puede pensarse desde distintos puntos de vista: en primer lugar, en la producción de libros electrónicos, así como en el uso concreto de formatos web para la difusión y la construcción de la imagen "virtual" de una editorial. En segundo lugar, como modo de comercialización. Y en tercer lugar, como modo de existencia y desarrollo de plataformas de identidad híbrida entre páginas web, comunidades al estilo de los blogs, y distribuidoras o librerías. 
Al entrar en la página web de BajaLibros.com, lo primero que se observa es este dinamismo en la exposición de los libros a través de sus portadas y valores. Aparecen las Revistas, los Géneros, los Autores independientes, y también ciertos procesos de marketing de la página, que son las "Recomendaciones" y los "Más vendidos". Se presenta entonces como una "librería virtual", una "tienda" que además de tener simplemente un buscador de los libros, se propone como un "librero virtual" capaz de recomendar libros sobre distintas temáticas. En esta misma línea, otra de las características que tiene la página es un Blog (Ver Figura 4), en donde aparecen en una suerte de revista, recomendaciones, frases de autores, y también el resumen de lo que los lectores compraron en el mes anterior. Sin embargo, al explorar la página web y las posibilidades de la plataforma, se observa también que al ofrecer servicios para los escritores que desean autopublicarse, puede inferirse que la plataforma también realiza acciones como "editor".

BajaLibros.com se presenta como una tienda de libros y cuenta con un extenso catálogo en ficción, bestsellers, autoayuda, cocina, y miles de ebooks de grandes grupos editoriales. Los ebooks se pueden ver y descargar en diferentes plataformas como dispositivos móviles de IOS y Android, e-readers, tablets y computadoras. También cuenta con una aplicación de lectura gratuita para descargar los libros electrónicos en los dispositivos. En una entrevista realizada al momento del surgimiento, Eugenia Bascarán, la representante de esta plataforma, afirmaba que "tenemos contratos con varias editoriales". Afirmaba que, al igual que una editorial de editoriales, intentan contar con un "catálogo" amplio que se actualice constantemente. Al comienzo, además de las descargas de libros con derecho de autor, proponían la descarga de libros gratuitos, para generar una vinculación y un conocimiento de la página/tienda/librería. En relación con la competencia planteada con Amazon. com, en esta entrevista ella afirmaba que esta tienda poseía una ventaja diferencial en el público argentino, ya que, al tener contacto y conocimiento con editoriales locales, eso les daba la posibilidad de pensar lanzamientos de libros conjuntos, contar con información previa sobre los libros, y como afirmaba "sinergizar acciones de marketing".

Acerca de la cuestión de la piratería, ella afirmaba que "las editoriales en nuestro país están muy preocupadas por la protección de los derechos de autor y esa preocupación era la principal barrera para animarse a entrar en el negocio del libro electrónico". Sin embargo, afirma que el uso del DRM es una condición fundamental para poder cerrar los acuerdos necesarios con la industria. Bajalibros.com es una plataforma única y está desarrollado íntegramente en PHP y MySQL. EI DRM es de Adobe y todos los equipos son de ellos. Respecto al formato de los ebooks, cuentan con un equipo de conversión que se ocupa de convertir los archivos que les entregan las editoriales a ePub. Otro tema fundamental es el tema de la venta/distribución de libros en español. Los libros se pueden comprar en cualquier parte del mundo, excepto cuando hay una restricción por el tema de derechos de autor. En esos casos, las editoriales son las que indican en qué territorios se pueden comercializar y se restringe la compra para los demás países.

Las percepciones sobre lo que es un libro y una librería que se desprenden del recorrido por la página web y por la mencionada entrevista, giran en torno al cambio de paradigma al que se enfrenta la producción de libros y el estadio diferente de instalación de ese paradigma si se compara a Argentina con los países europeos o Estados Unidos. En esta perspectiva, el libro electrónico representa al libro en papel la misma transformación que la invención de la imprenta ya que la digitalización trajo aparejada la ventaja de la masividad y la portabilidad que se acrecientan a partir del libro electrónico, por lo que el editor entiende que en la digitalización está la clave de la sustentabilidad. La cuestión de la digitalización representa una nueva variable de análisis del campo editorial, que se agrega a la diferenciación previa que existía entre editoriales independientes/concentradas. Así, la 
variable digital/analógico trae una nueva posibilidad para pensar el lugar en que las librerías y editoriales pueden ubicarse y pensarse.

\section{Consideraciones finales}

Este caso nos permitió explorar una cuestión central de la década del 2000: la relación que los actores de un campo editorial periférico como el argentino mantienen con las tecnologías. En este artículo hemos analizado el caso de un modelo de librería-distribuidora emergente que se identifica con la edición y distribución digital. El abordaje de este caso muestra el grado de inestabilidad y dinamismo de los negocios editoriales en el medio digital, que se mueve en un escenario híbrido entre los libros en papel y los libros electrónicos. Asimismo, los editores tratan de sostener plataformas digitales que muestren pero también puedan comercializar contenidos, si bien la hegemonía de plataformas de venta como Amazon parece insoslayable. Además, las herramientas digitales han permitido acercar las diferencias que existían entre las pequeñas y grandes editoriales, ya que las editoriales pequeñas, por sus características de menor escala, son más livianas y tienen más posibilidades para reconvertirse hacia nuevas modalidades de edición.

A lo largo de este trabajo hemos visto la emergencia de prácticas y soportes que establecen una circulación virtual de contenidos textuales que progresivamente convive con las tradicionales instituciones del campo. Las figuras del editor, autor y lector, así como las del distribuidor y las librerías se encuentran en permanente transformación, y sus funciones y modos de interacción han ido reconfigurándose a partir de la apropiación social de las nuevas tecnologías y las transformaciones de las últimas décadas que se dieron en el interior del campo editorial. De este modo, intentamos por último mostrar un caso de análisis constituido por la primera plataforma de venta de ebooks argentina que se propone entrar enteramente al comercio de libros en formato digital. Tal como se anticipó en la descripción de las herramientas aparecidas durante la última década, los procesos de escritura, edición y lectura ya no son sucesivos, sino que se entretejen continuamente, provocando la aparición de nuevas prácticas, actores y una reconfiguración de las categorías que teorizan sobre el sistema literario y de edición, que han sido largamente estudiados además por distintos especialistas del campo editorial en estas temáticas, como Elizabeth Hutnik (2012), Diego Vigna (2014), o Claudia Kozak (2006).

A partir de las posibilidades de la tecnología, es posible que la producción de escritura ya no se encuentre separada, ni siquiera temporalmente, del momento de edición y publicación, como puede observarse a partir del caso de Bubok. Por otra parte, -y es un tema fundamental aunque no lo hemos abordado en este artículo- la aparición de las nuevas tecnologías, la expansión de los blogs y redes sociales como Twitter y Facebook en la creación, circulación y difusión literaria, aportan activamente al desarrollo de una esfera pública de lo literario, gracias a las relaciones comunitarias que se tejen entre escritores, lectores e intermediarios. Estas redes no se mantienen exclusivamente en la virtualidad, sino que tienen su correlato en proyectos editoriales y literarios concretos, presentaciones de libros, lecturas en vivo, etc. (Vanoli y Saferstein, 2011).

En distintos trabajos se han propuesto modelos de análisis para sistematizar y evaluar cuáles son y serán en el futuro los niveles de adaptación al paradigma digital. Joana CostaKnufinke, por ejemplo, propone algunos indicadores que nos permitirán evaluar el nivel de adaptación de emprendimientos del mundo editorial a esta nueva situación. Así, plantea por ejemplo observar el porcentaje de contratos de Derecho de Autor adaptados a la publicación en formato digital; el porcentaje de libros digitalizados del fondo editorial; el porcentaje de libros vendidos en formato ebook; el número de plataformas de venta de ebooks, el número de editoriales digitales y 
proporción en el total de editoriales; el número de e-readers, el porcentaje de libros que se publican en ambos formatos; el porcentaje de facturación del canal digital en relación al total, y el porcentaje de libros digitalizados con contenidos enriquecidos en relación al total. (Costa-Knufinke, 2010).

Sin embargo, es difícil establecer cómo se desarrollarán estas tendencias en el futuro, por lo que este trabajo concluye planteando nuevos interrogantes que surgen del análisis: ¿En qué lugar quedará la cultura escrita? ¿Cuál será el rol del editor y las librerías en el futuro? ¿Cuál será la forma que asuman las editoriales? ¿Reemplazará el libro electrónico al libro en papel? ¿Seguirá habiendo editores, editoriales y librerías? Es innegable afirmar que estamos en una etapa de transición, en la cual la hibridez de algunos proyectos descriptos en este trabajo (como la plataforma/librería virtual Bajalibros.com, así como la Editorial Teseo por mencionar un caso de editorial digital surgida en los últimos años en Argentina) es emblemática de los cambios culturales que transforman permanentemente la idea de lectura, escritura, autoría y creación. Sin embargo, debemos esperar para poder analizar cuál será en el futuro el impacto de este paradigma digital en el campo editorial local y en sus derivas internacionales.

Notas

1. El abordaje cualitativo supuso describir la página web de BajaLibros.com tanto en las imágenes como en los textos que allí se presentan, así como analizar distintas entrevistas realizadas a sus gestores.

Bibliografía de referencia

Aguirre, J. (1997). "La incidencia de las redes de comunicación en el sistema literario", en Revista Espéculo núm. 5, Madrid.

Bourdieu, P. (2000). Las reglas del arte. Barcelona: Anagrama.

Bourdieu, P. (2010). El sentido social del gusto. Buenos Aires: Siglo XXI.

Carlón, M. (2010). “La mediatización del mundo del arte”, en Fausto Neto, A. y Valdettaro, Sandra. (Dir) Mediatización, sociedad y sentido. Diálogos entre Brasil y Argentina: UNR.

Carlon, M. y Scolari, C. (comp.) (2009). El fin de los medios masivos. Buenos Aires: La Crujía.

Castells, M. (2001). Internet y la sociedad red. Madrid: Alianza Editorial.

Chartier, R. (2006). Inscribir y borrar. Buenos Aires: Fondo de Cultura Económica.

Colleu, G. (2008). La edición independiente como herramienta protagónica de la bibliodiversidad. Buenos Aires: La Marca Editora.

Costa-Kufinke, J. (2010). "Adaptación de las editoriales españolas al libro electrónico". En El profesional de la información vol. 19, número 1, pp. 13-20. 
Dantas, M. (2003). “Informação e trabalho no capitalismo contemporâneo". En Lua Nova: Revista de Cultura e Politica, $N^{\circ} 60$, pp. 5-44.

Darnton, R. (2010). El beso de Lamourette. Reflexiones sobre historia cultural. Buenos Aires: Fondo de Cultura Económica.

Ensinck, M. (2010). “El libro electrónico llegó para quedarse”. En ADN-La Nación, 169, pp. 4-8, 5 de noviembre.

Featherstone, M. (1991). Cultura de consumo y posmodernismo. Buenos Aires: Ed. Amorrortu.

Finkelstein, D. y Mccleery, B. (2014). Una introducción a la historia del libro. Buenos Aires: Paidós.

Fumero, A. y Sáez Vacas, F., (2006). "Blogs: en la vanguardia de la nueva generación web”. En Novática interactiva. Sociedad de la información, № 183, pp. 68-73.

García Canclini, N. (2007). Lectores, espectadores e internautas. Buenos Aires: Gedisa.

Goody, J. (comp.) (1996). Cultura escrita en sociedades tradicionales. Barcelona: Gedisa.

Harvey, D. (1991). La condición de la posmodernidad. Barcelona: Ed. Amorrortu.

Hutnik, E. y Saferstein, E. (2014). "Las prácticas de lectura en el entorno digital: industria editorial, mercado y consumo". Revista de Literaturas Modernas Vol. 44, № 1, ene.-jun., pp. 37-68.

Hutnik, E. (2012). "Reproducción, norma y valor en el entorno digital: Google Books o la biblioteca de la discordia”. Primer Coloquio Argentino sobre el Libro y la Edición. La Plata, noviembre. (ponencia).

Kozak, C. (comp.) (2006). Deslindes. Ensayos sobre literatura y sus límites en el siglo XX. Rosario: Beatriz Viterbo.

Kulesz, O. (2011). La edición digital en los países en desarrollo. París: Alianza Internacional de Editores.

Manovich, L. (2006). El lenguaje de los nuevos medios de comunicación, Barcelona: Paidós.

Mendoza, J. (2011). El canon digital. Buenos Aires: La Crujía.

Moulier Boutang, Y. (2004). Capitalismo Cognitivo, Propiedad Intelectual y Creación Colectiva. Madrid: Traficantes de sueños.

Neiman, G. y Quaranta, G. (2006). “Los estudios de caso en la investigación sociológica”. En Estrategias de investigación cualitativa, pp. 213-234. Barcelona: Gedisa.

Ong, W. (1982). Oralidad y escritura. Tecnologías de la palabra. México: Fondo de Cultura Económica.

Piscitelli, A. (2006). Nativos digitales. Buenos Aires: Santillana. 
Roldán, M. (2008). "Capitalismo Informacional, industrias de la comunicación y organización del trabajo en la producción de contenidos en la rama editorial. Reflexiones sobre su contribución al desarrollo en la Argentina 2000s" en Susana Sel (Comp.). Imágenes, palabras e industrias de la Comunicación. Estudios sobre el capitalismo informacional contemporáneo. Buenos Aires: La Tinta ediciones.

Shiner, L. (2004). La invención del arte. Una historia cultural. Barcelona: Paidós.

Vigna, D. (2008). "Literatura y soportes digitales: La irrupción del blog en el sistema literario actual del país". Ponencia presentada en XII Jornadas Nacionales de Investigadores en Comunicación: "Nuevos escenarios y lenguajes convergentes". Rosario. Disponible en:

http://www.redcomunicacion.org/memorias/pdf/2008Viponencia\%20vigna,\%20 diego\%20ok.pdf

Abstract: The digitalization of content has changed the techniques of editorial production and reading practices. In this article we will cover theoretically the changes that have occurred in the publishing chain of editorial content. Then we will describe the emergence of new media and actors that complicate the traditional instances of printed culture (mobile devices, influence of social networks on digital reading, online store development, the emergence of virtual libraries, etc.). Finally, we will analyze a case to understand these transformations: the online platform for selling ebooks Bajalibros.com, which is presented as "the first store of Spanish digital books in Latin America".

Key words: Digitalization - Editor - Bookstores - Ebooks - Platforms.

Resumo: A digitalização do conteúdo mudou as técnicas de produção editorial e práticas de leitura. Neste artigo, abordaremos teóricamente as mudanças ocorreram na cadeia de publicação de conteúdo editorial. Então descreveremos a emergência de novos apoios e atores que complicam as instâncias tradicionais de cultura impressa (dispositivos móveis, influência das redes sociais na leitura digital, desenvolvimento de lojas online, emergência de bibliotecas virtuais, etc.). Finalmente, analisaremos um caso para entender essas transformações: a plataforma on-line para a venda de ebooks Bajalibros.com, que é apresentada como "a primeira livraria digital em espanhol na América Latina".

Palavras chave: Digitalização - Editor - Bibliotecas - Ebooks - Plataformas.

[Las traducciones de los abstracts al inglés y portugués fueron supervisadas por el autor de cada artículo]

Configuraciones emergentes de circulación y lectura en el entorno digital: el caso de Bajalibros.com fue publicado de la página 151 a página165 en Cuadernos del Centro de Estudios de Diseño y Comunicación №72 